\title{
Hoffnung für die Pflege?
}

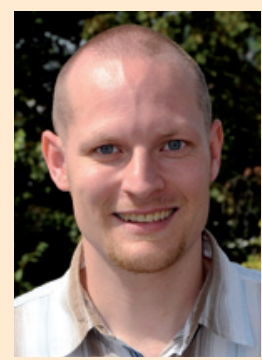

Christian Schäfer, Stuttgart
Wenn man an die vergangenen Jahre zurückdenkt, ist - außer großer Ankündigungen - im Pflegesektor wenig passiert. 2011 sollte bekanntlich das „Jahr der Pflege“ werden, wie Ende 2010 der damalige Bundesgesundheitsminister Philipp Rösler (FDP) vollmundig ankündigte. Was daraus geworden ist, spüren Pflegekräfte und Patienten heute alltäglich: Dass sich (immer noch nicht entscheidend besser bezahlte) Pflegekräfte um immer mehr Patienten kümmern müssen - dies ist sowohl ein Gesundheitsrisiko für Pflegekräfte (Stichwort „Burnout“) als auch für die Patienten (Stichwort „höhere Fehlerquote“). Und dieser Trend ist noch nicht abgeschlossen - im Gegenteil: Ändert sich nichts an den Rahmenbedingungen, fehlen im Jahr 2030 mehr als 400000 Pflegekräfte (nachzulesen auch im Artikel „Pflegekammer - Heilmittel oder Placebo für die Pflege?“ ab Seite 12 in Dialyse aktuell 1/2014).

Doch sieht es so düster aus mit der Zukunft der Pflege? Schauen wir uns hierzu einmal die Gegebenheiten in der deutschen Politik an: Seit Ende 2013 hat sich die Große Koalition aus CDU, CSU und SPD konstituiert. Man mag davon halten, was man will, aber für größere Reformen könnte sich diese politische Konstellation als günstig erweisen. So könnte mit komfortablen Mehrheitsbeschlüssen die Entwicklung recht schnell und leicht vorangetrieben werden - so Bundesgesundheitsminister Hermann Gröhe (CDU) \& Co. dies denn wollen.

Die Vorzeichen hierfür sind glücklicherweise verhältnismäßig gut: Ein großer Reformstau hat sich in den letzten Jahren und Jahrzehnten in der Pflege angesammelt - hier muss einfach bald etwas passieren. Der Frust über das gescheiterte „Jahr der Pflege“ und die weiterhin mangelnde Anerkennung der Leistung von Pflegekräften sitzt tief - hier kann man es sich nicht mehr leisten, die große Gruppe von Wählern aus dem Gesundheitssektor zu ignorieren. Es sind auch schon erste Vorarbeiten zu weiteren Reformen gemacht worden hierauf kann man aufbauen. Außerdem könnte man mit einer gesteigerten Attraktivität des Berufsbildes durch mehr Gehalt und bessere Arbeitsbedingungen sicherlich einige Menschen dazu bringen, einen Pflegeberuf zu ergreifen. Dies hätte positive Auswirkungen auf die Volkswirtschaft: Wie z.B. das Zentrum für Europäische Wirtschaftsforschung (ZEW) berechnet hat, brächten 100000 neue Arbeitsplätze ein Plus von 57 Milliarden Euro für das Bruttoinlandsprodukt (BIP) - und damit ließe sich Werbung beim Wähler machen bzw. getätigte Ausgaben wären damit leichter auszugleichen. Immer mehr Studien zeigen zudem auf, dass sich der Fachkräftemangel und die Alterung der Bevölkerung nicht mehr länger wegreden lassen - zu groß sind schon jetzt die Probleme, die damit zusammenhängen, bzw. die Probleme der Zukunft sind schon bald die der Gegenwart.

Man sieht, dass trotz der gegenwärtig relativ schlechten Lage eigentlich ein verhaltener Optimismus durchaus angebracht ist, wenn man über die Situation der Pflege nachdenkt. Immer mehr und zunehmend auch medienwirksame sowie gesellschaftlich präsente und relevante Punkte sprechen für eine grundsätzliche Reform der Pflege in Deutschland. Oder: Es kann nur und muss aufwärts gehen!

In dieser Ausgabe der Dialyse aktuell geht es um ein Thema, das analog zur Pflegefrage in der Politik von Zeit zu Zeit in der Versenkung zu verschwinden droht - nur, um dann aufgrund seiner Wichtigkeit immer wieder hochzukochen: die Hygiene. Nichts entkommt bei Zeitmangel leichter dem Radar der Aufmerksamkeit wie etwas, das man mit bloßem Auge gar nicht sieht. Daher haben wir den Schwerpunkt des vorliegenden Hefts auf Wissenswertes rund um den Kampf gegen die mikroskopisch kleinen Übeltäter bei der Dialyse - Krankheitserreger aller Art - gelegt. Denn nur mit der korrekten Anwendung von Desinfektionsmitteln und genügend Wissen rund um die Hygiene kann man unangenehmen und gefährlichen Situationen für die Betreiber, das Personal und die Patienten einer Dialyseeinrichtung vorbeugen. Diese Ausgabe dient als Fortführung und Ergänzung der bisherigen Schwerpunktausgaben rund um die Hygiene und Infektionen bei der Dialyse (Dialyse aktuell 6/2011, 5/2012 und 3/2013). Ich wünsche Ihnen eine aufschlussreiche Lektüre! 